\title{
Patients with MS under daclizumab therapy mount normal immune responses to influenza vaccination
}

\section{OPEN}

Yen Chih Lin, PhD

Paige Winokur, BS

Andrew Blake, BS

Tianxia Wu, PhD

Jody Manischewitz, MS

Lisa R. King, BS

Elena Romm, MS

Hana Golding, PhD

Bibiana Bielekova, MD

Correspondence to

Dr. Bielekova:

bibi.bielekova@nih.gov

Supplemental data at Neurology.org/nn

\section{ABSTRACT}

Objective: The purpose of this study was to assess the potential immunosuppressive role of daclizumab, a humanized monoclonal antibody against the $\alpha$ chain of the interleukin 2 receptor, in vivo, by comparing immune responses to the 2013 seasonal influenza vaccination between patients with multiple sclerosis (MS) on long-term daclizumab therapy and controls.

Methods: Previously defined subpopulations of adaptive immune cells known to correlate with the immune response to the influenza vaccination were evaluated by 12 -color flow cytometry in 23 daclizumab-treated patients with MS and $14 \mathrm{MS}$ or healthy controls before (D0) and 1 day (D1) and 7 days (D7) after administration of the 2013 Afluria vaccine. Neutralizing antibody titers and $\mathrm{CD}^{+}{ }^{+}, \mathrm{CD}^{+}{ }^{+} \mathrm{T}$ cell, B cell, and natural killer cell proliferation to 3 strains of virus contained in the Afluria vaccine were assessed at D0, D7, and 180 days postvaccination.

Results: Daclizumab-treated patients and controls demonstrated comparable, statistically significant expansions of previously defined subpopulations of activated CD8 ${ }^{+} \mathrm{T}$ cells and $\mathrm{B}$ cells that characterize the development of effective immune responses to the influenza vaccine, while proliferation of T cells to influenza and control antigens was diminished in the daclizumab cohort. All participants fulfilled FDA criteria for seroconversion or seroprotection in antibody assays.

Conclusion: Despite the mild immunosuppressive effects of daclizumab in vivo demonstrated by an increased incidence of infectious complications in clinical trials, patients with MS under daclizumab therapy mount normal antibody responses to influenza vaccinations. Neurol Neuroimmunol Neuroinflamm 2016;3:e196; doi: 10.1212/NXI.0000000000000196

\section{GLOSSARY}

$\mathbf{A b}=$ antibody; $\mathbf{A g}=$ antigen; $\mathbf{C M V}=$ cytomegalovirus; DAC-HYP $=$ daclizumab high-yield process; $\mathbf{D C}=$ dendritic cell; $\mathbf{E B V}=$ Epstein-Barr virus; Flu-HA = influenza hemagglutinin; $\mathbf{I g}=$ immunoglobulin; IL-2R = interleukin 2 receptor; ILC = innate lymphoid cell; $\mathbf{M S}=$ multiple sclerosis; $\mathbf{N K}=$ natural killer; PBMC = peripheral blood mononuclear cell; $\mathbf{R R M S}=$ relapsing-remitting multiple sclerosis.

Daclizumab high-yield process (DAC-HYP [Biogen Idec, Boston, MA, and AbbVie Inc., North Chicago, IL]), a humanized monoclonal antibody (Ab) against CD25, the $\alpha$ chain of the high-affinity interleukin 2 receptor (IL-2R) with proven clinical efficacy in multiple sclerosis (MS), ${ }^{1,2}$ was conceptually developed as a selective blocker of activated T cells, because T cells upon activation upregulate CD25 and consume IL-2. ${ }^{3}$ Although in vitro studies using nonphysiologically high concentrations of daclizumab supported a direct inhibitory role of daclizumab on $\mathrm{T}$ cells, polyclonally activated $\mathrm{T}$ cells isolated from patients under daclizumab therapy had unhindered proliferation and cytokine production. ${ }^{4,5}$ Conversely, via inhibition of activation-induced cell death ${ }^{6,7}$ and FoxP3 ${ }^{+}$regulatory $\mathrm{T}$ cells, ${ }^{8,9}$ daclizumab augments survival of activated $\mathrm{T}$ cells in vivo. Consistent with these observations, both CD25-deficient mice and humans experience lymphoproliferation. ${ }^{10-12}$ However, CD25-deficient humans are

\footnotetext{
From the Neuroimmunological Diseases Unit, Neuroimmunology Branch (Y.C.L., P.W., A.B., E.R., B.B.) and Clinical Neuroscience Program (T.W.), National Institute of Neurological Diseases and Stroke, NIH, Bethesda, MD; FDA (J.M., L.R.K., H.G.), CBER; and NIH Center for Human Immunology (B.B.), NIH, Bethesda, MD.

Funding information and disclosures are provided at the end of the article. Go to Neurology.org/nn for full disclosure forms. The Article Processing Charge was paid by NINDS.

This is an open access article distributed under the terms of the Creative Commons Attribution-NonCommercial-NoDerivatives License 4.0 (CC BY-NC-ND), which permits downloading and sharing the work provided it is properly cited. The work cannot be changed in any way or used commercially.
} 


\begin{tabular}{|c|c|c|c|}
\hline Table 1 & $\begin{array}{l}\text { timized combination of commercially availab } \\
\text { d ROR } \mathrm{rt}^{+} \text {immune cells }\end{array}$ & le fluorochrome-conjugated antibodies to relial & oly quantify T cell and monocyte, B cell \\
\hline Conjugation & $\mathrm{T}$ cell and monocyte & B cell & Intracellular staining \\
\hline FITC & Anti-human CD69 antibody (BD, FN50) & Anti-human CD40 antibody (Invitrogen, HB14) & Anti-human CD56 antibody (BD, MEM188) \\
\hline PE & Anti-human CD40 antibody (BioLegend, HD14) & $\begin{array}{l}\text { Anti-human CD21 antibody (Beckman Coulter, } \\
\text { A32524) }\end{array}$ & $\begin{array}{l}\text { Anti-human ROR } \gamma \delta \text { antibody (R\&D, } \\
600380 \text { ) }\end{array}$ \\
\hline PerCP-Cy5.5 & Anti-human HLA-DR antibody (BD, Tu36) & Anti-human $\mathrm{CD} 2 \mathrm{O}$ antibody $(\mathrm{BD}, 2 \mathrm{H} 7)$ & $\begin{array}{l}\text { Anti-human CD123 antibody (eBioscience, } \\
7 G 3 \text { ) }\end{array}$ \\
\hline PE-Cy7 & Anti-human CD86 antibody (BioLegend, IT2.2) & Anti-human CD86 antibody (BioLegend, IT2.2) & $\begin{array}{l}\text { Anti-human CD11c antibody (eBioscience, } \\
\text { 3.9) }\end{array}$ \\
\hline V450 & Anti-human CD4 antibody (BD, RPA-T4) & Anti-human CD80 antibody (BD, L307.4) & Anti-human CD45 antibody (BD, HI30) \\
\hline $\begin{array}{l}\text { Brilliant Violet } \\
510\end{array}$ & $\begin{array}{l}\text { Anti-human CCR7/CD197 antibody (BioLegend, } \\
\text { G043H7) }\end{array}$ & Anti-human IgM antibody (Biolegend, MHM-88) & \\
\hline AmCyan & & & Anti-human CD8 antibody (BD, SK1) \\
\hline Qdot 605 & Anti-human CD8 antibody (Invitrogen, 3B5) & Anti-human CD27 antibody (Invitrogen, CLB-27/1) & $\begin{array}{l}\text { Anti-human CD19 antibody (eBioscience, } \\
\text { HIB19) }\end{array}$ \\
\hline Qdot 655 & Anti-human CD14 antibody (Invitrogen, TuK4) & Anti-human CD19 antibody (Invitrogen, SJ25-C1) & $\begin{array}{l}\text { Anti-human CD3 antibody (eBioscience, } \\
\text { OKT3) }\end{array}$ \\
\hline Qdot 705 & & & $\begin{array}{l}\text { Anti-human CD } 4 \text { antibody (Invitrogen, } \\
\text { S3.5) }\end{array}$ \\
\hline Qdot 800 & Anti-human CD45 antibody (Invitrogen, H130) & Anti-human CD45 antibody (Invitrogen, H130) & \\
\hline APC & Anti-human CD25 antibody (BioLegend, M-A251) & Anti-human IgD antibody (BioLegend, HIT2) & \\
\hline Alexa Fluor 700 & Anti-human CD38 antibody (BioLegend, HIT2) & $\begin{array}{l}\text { Anti-human CD38 antibody (MACS Miltenyi, } \\
\text { 130-094-553) }\end{array}$ & $\begin{array}{l}\text { Anti-human CD14 antibody (BioLegend, } \\
\text { HCD14) }\end{array}$ \\
\hline APC-Cy 7 & Anti-human CD3 antibody (BioLegend, SK7) & Anti-human CD10 antibody (BioLegend, HI10a) & $\begin{array}{l}\text { Anti-human HLA-DR antibody (eBioscience, } \\
\text { LN3) }\end{array}$ \\
\hline
\end{tabular}

Abbreviations: $B D=$ Becton Dickinson; FITC = fluorescein isothiocyanate; IgM = immunoglobulin $M ; R \& D=R \& D$ Systems.

Presented as name of antibody (company, clone).

also immunocompromised, and daclizumab treatment causes a slight increase in infectious complications in phase $\mathrm{II}^{13-15}$ and phase III trials. $^{1,2}$

Trying to explain this apparent paradox, we discovered that daclizumab limits activation/ priming of antigen (Ag)-specific $\mathrm{CD}^{+}$and $\mathrm{CD}^{+} \mathrm{T}$ cells indirectly, by limiting dendritic cell (DC)-mediated trans-presentation of IL2. ${ }^{5}$ This early IL-2 signal, delivered at the time when naive $\mathrm{T}$ cells do not yet express highaffinity IL-2R, is crucial for their differentiation to $\mathrm{T}$ cell effectors. Daclizumab also has unanticipated effects on innate lymphoid cells (ILCs), promoting differentiation of ILC precursors away from proinflammatory lymphoid tissue inducer (subtype of ILC3) cells and toward CD56 $6^{\text {bright }}$ natural killer (NK) cells. ${ }^{7,16}$ These immunoregulatory NK cells can kill activated autologous $\mathrm{T}$ cells, ${ }^{16,17}$ thus providing overlapping functions with regulatory $\mathrm{T}$ cells.

These multiple and unique mechanisms of action underlie efficacy of daclizumab in relapsing-remitting MS (RRMS). ${ }^{1,2,13-15}$ The question remains how potently immunosuppressive daclizumab therapy really is: will described effect on innate immunity prevent activation of $\mathrm{CD}^{+}, \mathrm{CD}^{+} \mathrm{T}$ cells and $\mathrm{B}$ cells/ plasma cells to common infectious pathogens? Therefore, the purpose of this study was to assess the potential immunosuppressive role of daclizumab in vivo, by comparing immune responses from patients with MS on long-term daclizumab therapy and controls to the seasonal influenza vaccination.

METHODS Standard protocol approvals, registrations, and patient consents. The study was approved by the NIH institutional review board and all patients provided written consent. The study was performed under investigational new drug application (IND 107973; IND sponsor: Bielekova/National Institute of Neurological Disorders and Stroke [NINDS]) as part of NINDS clinical trial 10-N-0125: "Investigating mechanism of action of DAC-HYP in the treatment of high-inflammatory multiple sclerosis (MS)" (ClinicalTrials.gov identifier NCT01143441).

Participants. Participant demographics and diagnosis are presented in table 1. Twenty-three patients with RRMS received DAC-HYP $150 \mathrm{mg}$ subcutaneously every 4 weeks for a minimum of 36 months; $60.9 \%$ (14/23) of these patients were treated with a previous formulation of daclizumab (Zenapax; Hoffmann-La Roche, Basel, Switzerland) for up to 6 years 
Figure 1 Flu immunization-induced changes in the proportions and absolute numbers of $\mathrm{T}$ cells and their relevant subpopulations

Abs
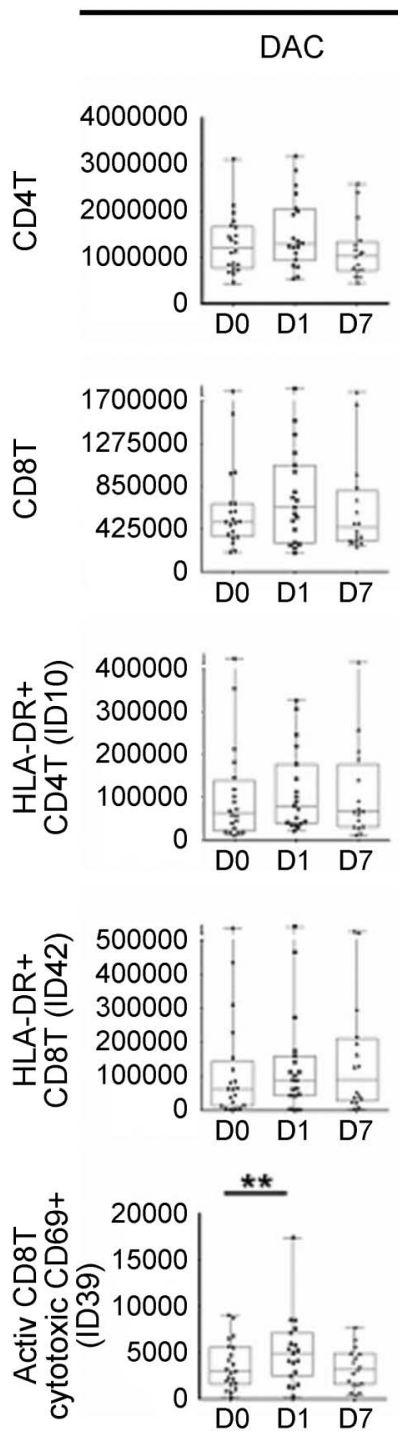
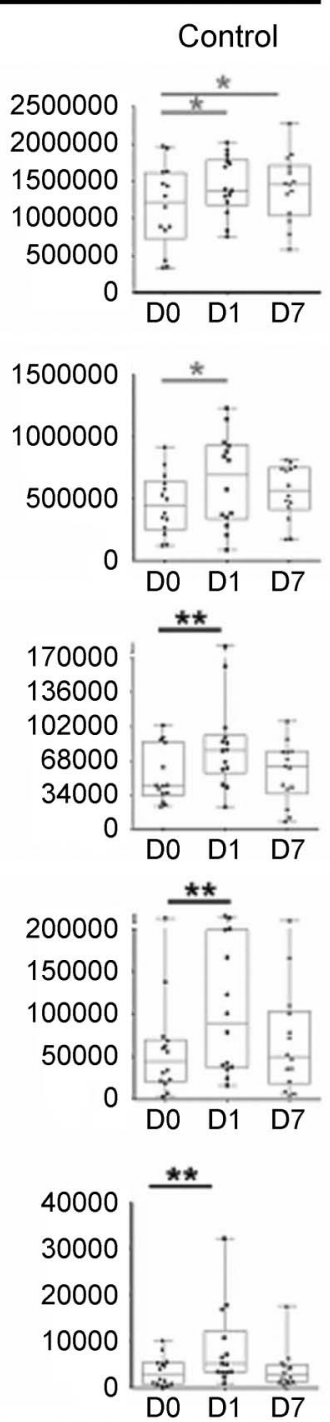
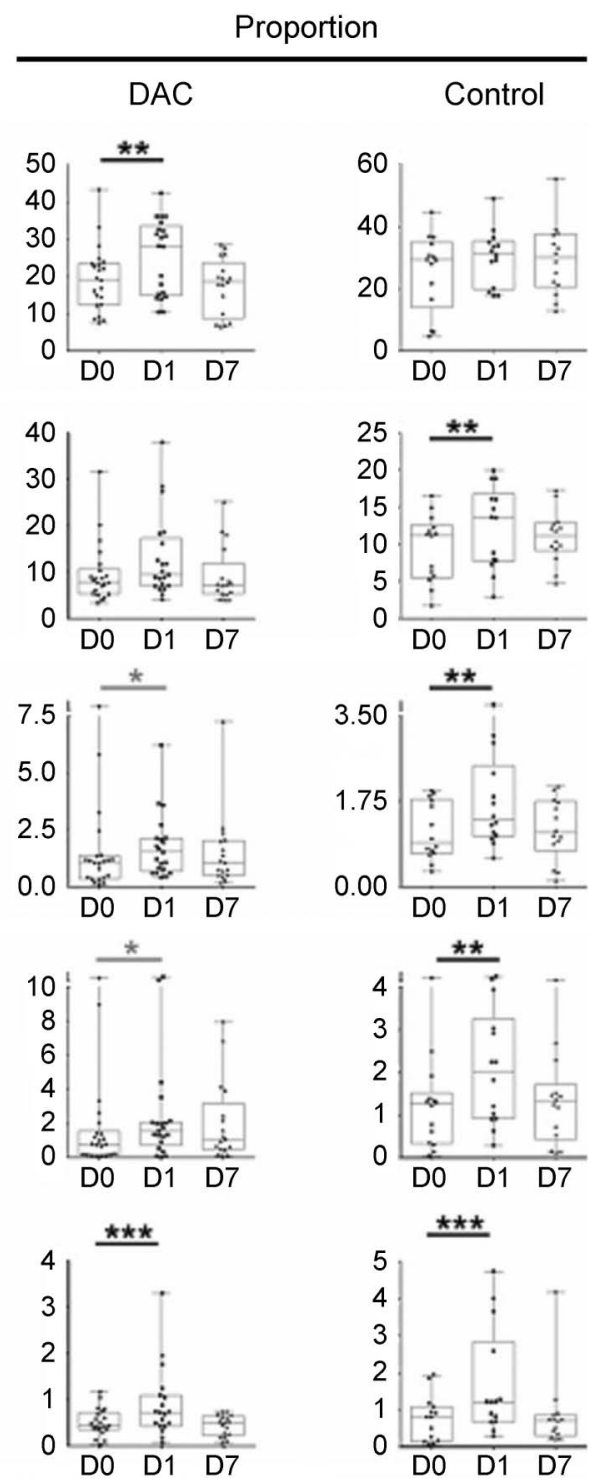

$\mathrm{CD}^{+}$and $\mathrm{CD}^{+} \mathrm{T}$ cells and their subsets that were previously shown to change in response to influenza vaccines (HLA-DR ${ }^{+}$ effector cells and CD69+-activated CD8 T cells) were assessed by multicolor flow cytometry before (D0) and 1 day (D1) and 7 days (D7) postimmunization with Afluria 2013 vaccine. The 2 left panels in each row represent absolute numbers of identified cell populations in the daclizumab-treated patients and controls, while the 2 right panels represent proportions of the same cell populations in the identical cohorts. The vertical box plots show the median and $25 \%-75 \%$ range, while the whiskers reflect minimum and maximum values for each diagnostic group. The scatter dot plots correspond to individual patient's data. $* p<0.05, * * 0.001<p<0.05, * * * p<0.001$. Abs $=$ antibodies; DAC $=$ daclizumab.

before enrollment in the $10-\mathrm{N}-0125$ protocol. DAC-HYP has the identical amino sequence of Zenapax, but because of expression in different cell types, its glycosylation changes affect its binding to $\mathrm{Fc}$ receptors. ${ }^{18}$ Controls (10 patients with RRMS and 4 controls with no evidence of CNS inflammation; see table e-1 at Neurology.org/nn for details) were prospectively recruited from the natural history protocol 09-N-0032 (table e1). Diagnosis of RRMS was based on the 2010 revisions to the McDonald diagnostic criteria. ${ }^{19}$ The local patients (DAC-HYP: $\mathrm{n}=17$; controls: $\mathrm{n}=14$ ) had sample collection and analysis performed at all time points (day 0 [D0], D1, D7, and D180) whereas patients requiring long-distance travel to NIH had analysis only at D0, D1, and D180 (DAC-HYP: $\mathrm{n}=6$; controls: none).
Sample preparation and peripheral blood mononuclear cell isolation. All samples were assigned an alpha-numeric code. Personnel generating data were blinded to the participants' diagnoses or treatment assignment. The data obtained from MS and non-MS controls were overlapping and therefore we did not sub-divide this control group based on diagnostic conclusions.

Peripheral blood mononuclear cells (PBMCs) were isolated from blood immediately after collection in LeucoSep tubes before the vaccine (D0), 1 day later (D1), and 7 days later (D7) according to manufacturer's instruction. Briefly, LeucoSep tubes were prepared by spinning $15 \mathrm{~mL}$ of lymphocyte separation medium (Lonza) at room temperature for 30 seconds at $1,000 \mathrm{~g}$. Twenty-five milliliters of freshly collected blood was added into tubes, which were then spun for 
Figure 2 Flu immunization-induced changes in the proportions and absolute numbers of B cells and their relevant subpopulations

Abs
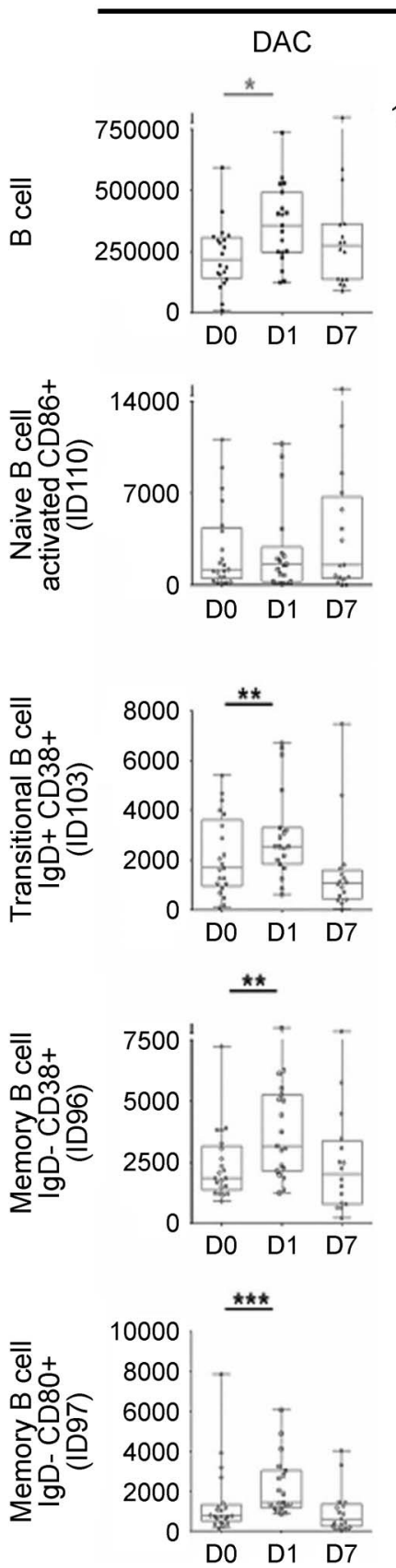
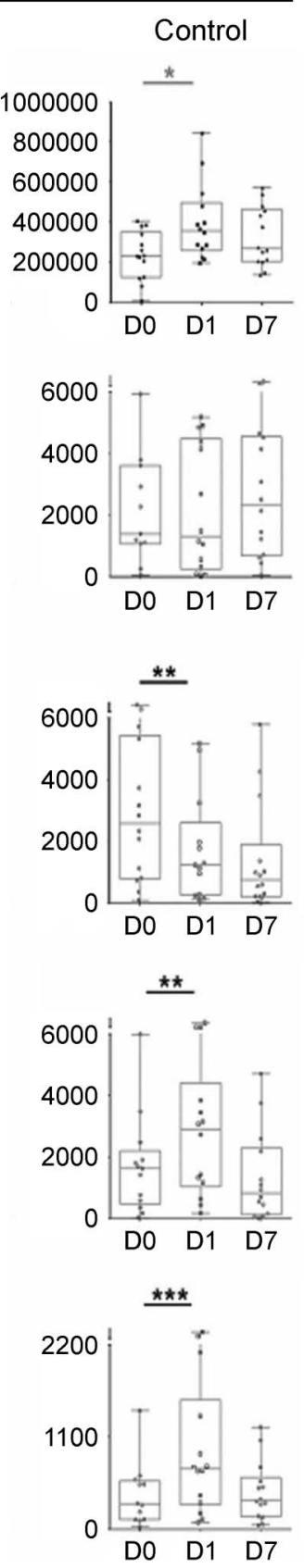
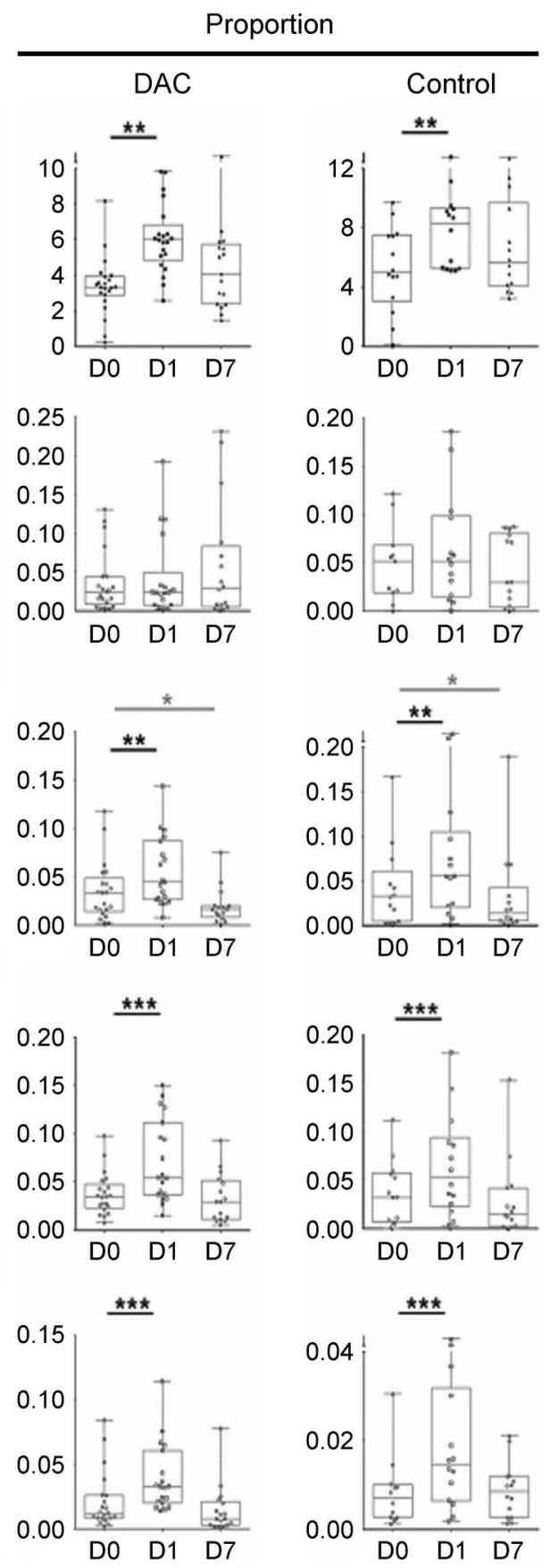

Proportion
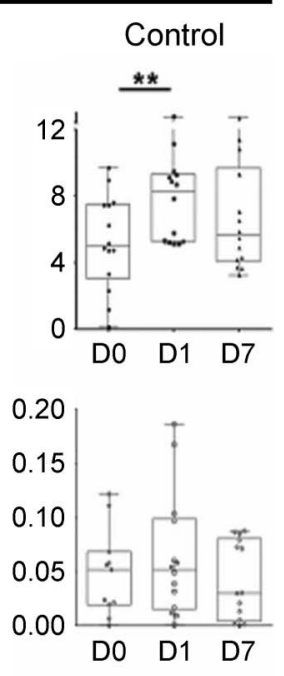

$\mathrm{CD} 19^{+} \mathrm{B}$ cells and their subsets (naive $\mathrm{CD} 6^{+} \mathrm{B}$ cells, transitional $\mathrm{lgD}^{+} / \mathrm{CD} 27^{+} / \mathrm{CD} 38^{+} \mathrm{B}$ cells, and 2 closely related populations of memory $\mathrm{B}$ cells: IgD $-/ \mathrm{CD} 27^{+} / \mathrm{CD} 38^{+}$and $\mathrm{lgD}-/ \mathrm{CD} 27^{+} / \mathrm{CD}^{-} 0^{+}$) were assessed by multicolor flow cytometry before (DO) and 1 day (D1) and 7 days (D7) postimmunization with Afluria 2013 vaccine. The 2 left panels in each row represent absolute numbers of identified cell populations in the daclizumab-treated patients and controls, while the 2 right panels represent proportions of the same cell populations in the identical cohorts. The vertical box plots show the median and $25 \%-75 \%$ range, while the whiskers reflect minimum and maximum values for each diagnostic group. The scatter dot plots correspond to individual patient's data. $* p<0.05, * * 0.001<p<0.05, * * * p<0.001$. Abs $=$ antibodies; DAC $=$ daclizumab; IgD = immunoglobulin D.

10 minutes under the same conditions. Monocytes were removed from the tube wall via scraping and the supernatants were transferred to new $50-\mathrm{mL}$ centrifugation tubes and washed twice. The cells were counted by hemocytometer and aliquotted between flow cytometry and Ag-specificity assays.
Autologous plasma was preserved for quenching the TraceCellViolet staining reaction (see below). Serum was collected at each time point into BD Vacutainer SST tubes (Becton Dickinson, Franklin Lakes, NJ), spun, aliquotted, and frozen $\left(-80^{\circ} \mathrm{C}\right)$ until analysis of neutralizing Abs, while remaining serum was used fresh for $\mathrm{T}$ cell Ag specificity assays. 
Abs
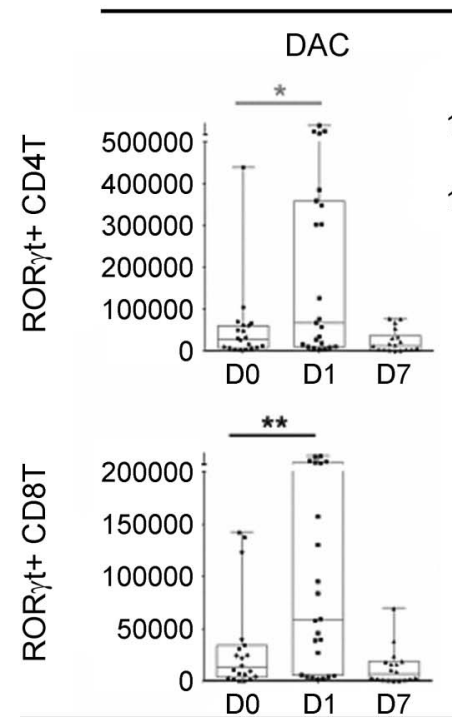
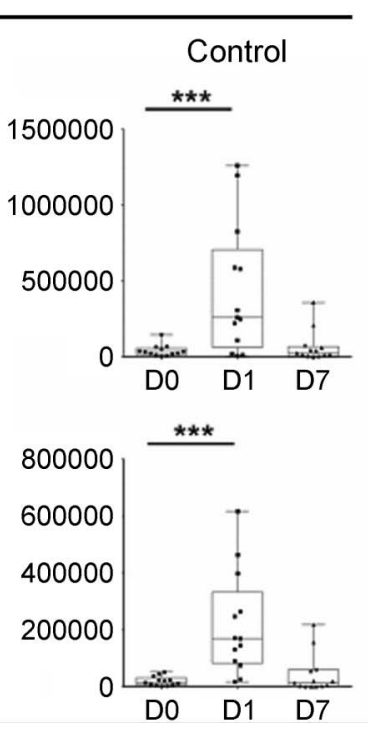

Proportion
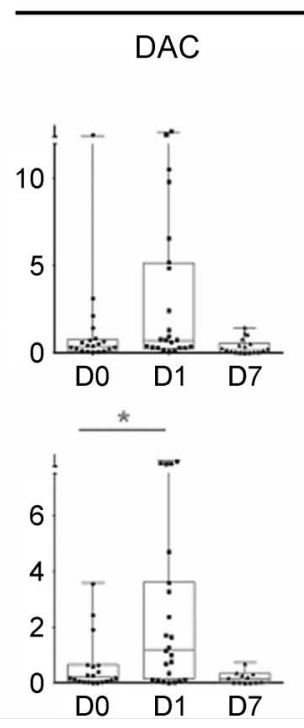
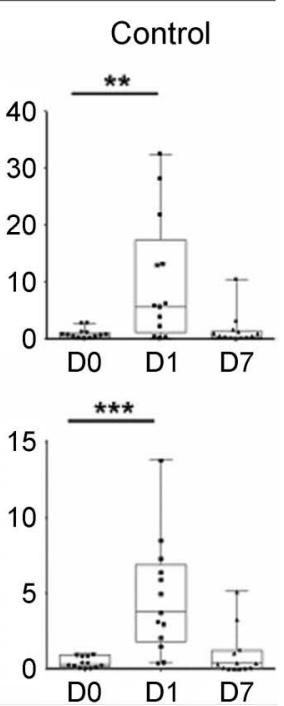

Expression of RORyt, the master regulator of Th17 lineage was assessed in $\mathrm{CD} 4^{+}$and $\mathrm{CD} 8^{+} \mathrm{T}$ cells by intracellular staining before (D0) and 1 day (D1) and 7 days (D7) postimmunization with Afluria 2013 vaccine. The 2 left panels in each row represent absolute numbers of identified cell populations in the daclizumab-treated patients and controls, while the 2 right panels represent proportions of the same cell populations in the identical cohorts. The vertical box plots show the median and $25 \%-75 \%$ range, while the whiskers reflect minimum and maximum values for each diagnostic group. The scatter dot plots correspond to individual patient's data. $* p<0.05, * * 0.001<p<0.05, * * * p<0.001$. Note the differences in scales between the daclizumab and control cohorts. Abs = antibodies; DAC $=$ daclizumab.

Ex vivo flow cytometry immunophenotyping. For ex vivo immunophenotyping, multicolor staining combinations were designed (table 1) to include $\mathrm{T}$ and $\mathrm{B}$ cell subpopulations that were found to be responsive to influenza vaccination in the previous study. ${ }^{20}$ The $2 \times 10^{6}$ blood cells (after lysing red blood cells) or PBMCs were stained according to a previously published proto$\mathrm{col}^{21}$ that includes blockade of $\mathrm{Fc}$ receptors by $2 \%$ IV immunoglobulin (Ig). For intracellular staining of ROR- $\gamma \mathrm{t}$, a minimum of $10^{6}$ blood cells were stained for surface markers. Then, cells were fixed by Cytofix/Cytoperm buffer and washed by Perm/Wash buffer (all BD Biosciences) before staining with intracellular Ab.

Cells were immediately acquired on a BD LSR II equipped with a High Throughput Sampler and analyzed with FACSDiva 6.1 software (all BD Biosciences). Gating was based on isotype controls (see figure e-1 for gating strategy).

T cell Ag specificity assay. PBMCs were stained with $5 \mu \mathrm{M}$ CellTraceViolet (Invitrogen, Carlsbad, CA) according to the manufacturer's protocol with the modification that saved autologous plasma was used for quenching of the staining reaction. After washing, CellTraceViolet-stained PBMCs were counted and resuspended in autologous serum and seeded at $1 \times 10^{6}$ cells/100 $\mu \mathrm{L} /$ well into U-bottom 96-well plates. Ags (influenza hemagglutinin [Flu-HA; Afluria vaccine], brain homogenate isolated from brain of a patient with MS obtained by rapid autopsy and prepared as described, ${ }^{22}$ and 2 control viral complex antigens: commercially available lysates of Epstein-Barr virus [EBV] and human cytomegalovirus [CMV; Advanced Biotechnology $]^{22}$ ) all used at $1 \mu \mathrm{g} / \mathrm{mL}$ final concentration were added to appropriate wells in $100 \mu \mathrm{L}$ of X-vivo medium and incubated at $37^{\circ} \mathrm{C}, 5 \% \mathrm{CO}_{2}$. On day 6 of incubation, wells that depleted nutrients and acidified medium were split into 2 new wells (in autologous serum to X-vivo medium at 1:1 ratio).
On day 9, cell pellets were collected and proliferation of different cell populations was assessed by flow cytometry, after surface staining with the following antibodies: CD19 (Mouse IgG1k Clone HIB19, BD Biosciences), CD56 (Mouse IgG1k Clone MY31, BD Biosciences), CD8 (Mouse IgG1k Clone RPA-T8, $\mathrm{BD}$ Biosciences), CD3 (Mouse IgG2a,k Clone OKT3, eBiosciences), and CD4 (Mouse IgG2b Clone OKT4, eBiosciences). Before acquisition by flow cytometer, $10 \mu \mathrm{L}$ SPHERO AccuCount Ultra Rainbow Fluorescent Particles was added to each well to proportionally enumerate cells between different Ag conditions.

Neutralizing Ab titers. Viral-neutralizing activity was analyzed by a microneutralization assay in MDCK cells using minor modifications of previously published methods of the pandemic influenza reference laboratories of the Centers for Disease Control and Prevention. ${ }^{23}$ Specifically, Ab-neutralization titers were measured against the 3 influenza strains in the inactivated influenza virus (TIV) vaccine used for immunization of study participants. Sera were tested at an initial dilution of 1:20, and those that were negative $(<1: 20)$ were assigned an arbitrary titer of 10 . All sera were tested in triplicate, using the geometric mean value for final analysis.

Statistical analysis. For each T cell or B cell expression, absolute numbers or proportions, the time effect (D0, D1, D7; or the difference between 3 time points) was examined for daclizumab and control group separately using 1 -way repeatedmeasures analysis of variance (figures 1-3) with a compound symmetry structure among the time levels. For each cell proliferation, the effect of condition (with 5 levels: control, $\mathrm{BM}, \mathrm{CMV}$, EBV, and Flu) was examined for daclizumab and control group separately using 1 -way analysis of variance 
Figure 4 Flu immunization-induced changes in cellular proliferation to exogenously added complex antigens
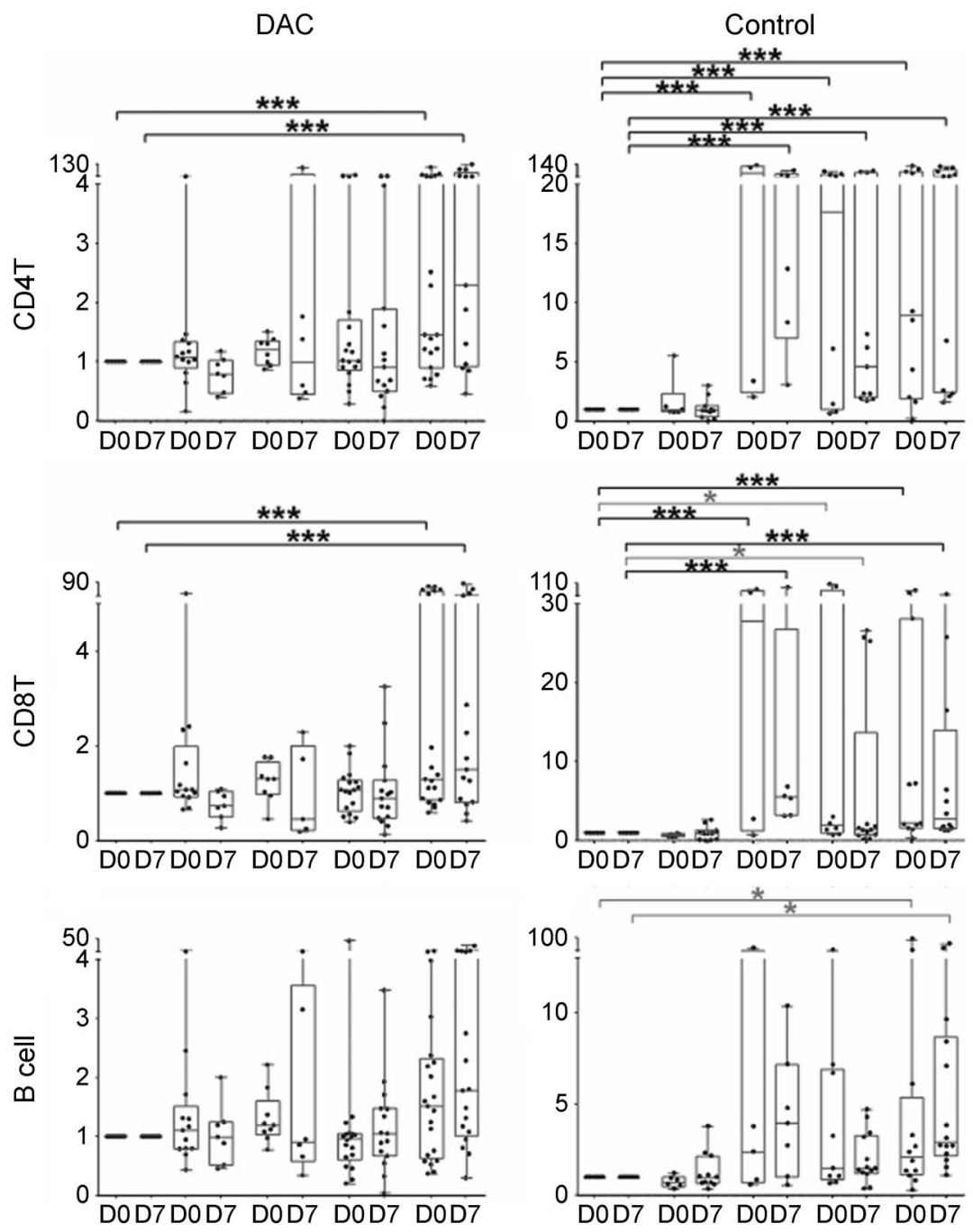
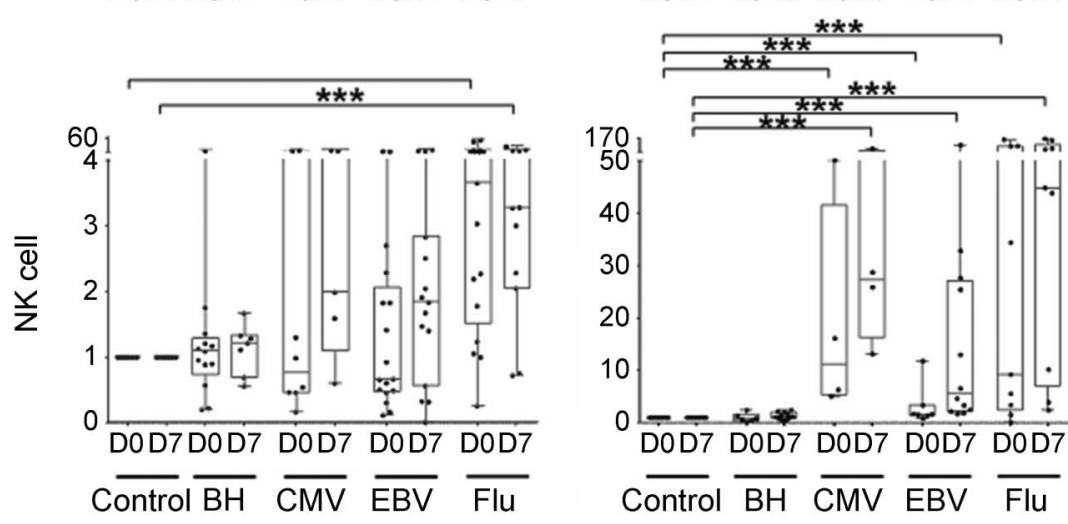

Freshly isolated peripheral blood mononuclear cells from blood samples collected before (DO) and 7 days (D7) after vaccination with Afluria 2013 vaccine were stained with CellTraceViolet vital fluorescent dye before addition of complex antigens (brain homogenate $[\mathrm{BH}]$, cytomegalovirus [CMV], Epstein-Barr virus [EBV], and Afluria 2013 vaccine [Flu]) in the presence of autologous serum (and therefore with in vivo-achievable concentrations of DAC-HYP in treated patients). Proliferation of $\mathrm{CD}^{+}$and $\mathrm{CD}^{+}{ }^{+} \mathrm{T}$ cells, B cells, and NK cells was measured 9 days later by quantifying proportion of cells that diluted CellTraceViolet and is expressed as stimulation index (ratio of proliferation measures in wells with exogenously added $\mathrm{Ag}$ as compared to control wells where no exogenous $\mathrm{Ag}$ was added). Results are depicted for daclizumab-treated patients (left column) and controls (right column). The vertical box plots show the median and $25 \%-75 \%$ range, while the whiskers reflect minimum and maximum values for each diagnostic group. The scatter dot plots (figure 4). For the B cell titers of 3 viruses in the Afluria vaccine, the time effect was evaluated for daclizumab and control group separately using a mixed model including time and virus effect with participants as random effect and a compound symmetry structure among the time levels within the virus. The interaction between time and virus and age, as covariate, were examined and dropped from the model.

Pairwise multiple comparisons between the 3 time levels or 5 condition levels using Tukey method were applied to the response variables with significant time (or condition) effect. As most of the response variables did not have normal distribution, BoxCox procedure was used to choose the power (or lambda) for data transformation. Shapiro-Wilk test was applied to the residuals for normality test. Statistical analyses were performed using SAS version 9.2 (SAS Institute, Cary, NC).

RESULTS Ex vivo immunophenotyping. We observed that seasonal Flu-HA immunization (Afluria 2013 vaccine) induced analogous statistically significant expansion of specific T cell (figure 1) and B cell (figure 2) subpopulations in the current study, as were previously described in relationship to 2009 seasonal and pandemic $\mathrm{H} 1 \mathrm{~N} 1$ Flu vaccines. ${ }^{20}$ Consistent with preexisting immunity observed in the majority of participants in both studied cohorts, the activation/expansion of the cells of adaptive immunity occurred early, 1 day postvaccination.

On the $T$ cell side, we observed significant increase in the absolute numbers and proportions of recently activated $\mathrm{HLA}-\mathrm{DR}^{+} \mathrm{CD}^{+}{ }^{+} \mathrm{T}$ cells (ID 10 in the original publication ${ }^{20}$ of Flu-induced immune changes on which the current study was designed; see figure e- 1 for gating strategy) and $\mathrm{HLA}-\mathrm{DR}^{+} \mathrm{CD} 8^{+}$ $T$ cells (ID42). In the daclizumab cohort, there was a trend for proportional expansion of these cells, which did not reach significance after adjustment for multiple comparisons. In contrast, $\mathrm{CD} 69^{+} \mathrm{CD}^{+} \mathrm{T}$ cells (ID39) were significantly expanded in both cohorts.

On the B cell side, Flu-HA induced proportional increase in B cells, which was entirely driven by both absolute and proportional increase in memory $\mathrm{B}$ cells: both $\mathrm{IgD}^{-} / \mathrm{CD} 27^{+} / \mathrm{CD} 8^{+}$(ID96) and $\mathrm{IgD}^{-} /$ $\mathrm{CD} 27^{+} / \mathrm{CD}^{+} 0^{+}$(ID97), which were expanded to similar and highly statistically significant levels in both cohorts. Transitional B cells $\left(\mathrm{IgD}^{+} / \mathrm{CD} 27^{-} /\right.$ $\mathrm{CD}^{+}{ }^{+}$; ID103) were expanded proportionally, but their absolute numbers varied between different participants, while naive-activated $\mathrm{B}$ cells $\left(\mathrm{IgD}^{+} /\right.$ $\mathrm{CD}^{-} 7^{-} / \mathrm{CD}^{2} 6^{+}$; ID110) were not influenced by Flu vaccination on a group level, consistent with the preexisting immune response in the majority of tested participants.

correspond to individual patient's data. $* p<0.05$, **0.001 $<\mathrm{p}<0.05, * * * \mathrm{p}<0.001 . \mathrm{Ag}=$ antigen; DAC $=$ daclizumab; DAC-HYP = daclizumab high-yield process; $\mathrm{NK}=$ natural killer. 
Intracellular staining for ROR $\boldsymbol{\gamma} \mathbf{t}$. Because IL-2 signaling was shown to antagonize Th17 differentiation, ${ }^{24}$ we asked whether Flu-HA-driven induction of the master regulator of Th17 T cells, ROR $\gamma \mathrm{t}$, is altered by daclizumab therapy. To answer this, we used intracellular staining for RORyt (table 1, last column). We reasoned that if IL-2 signaling inhibits Th17 differentiation, then inhibiting IL-2 signaling during evolving immune response by daclizumab would enhance Th17 differentiation, which could be detected by increased ROR $\gamma$ t expression in T cells. Contrary to this assumption, while we observed increased absolute numbers and proportions of ROR $\gamma \mathrm{t}$ expressing $\mathrm{CD}^{+}$and $\mathrm{CD}^{+} \mathrm{T}$ cells in both cohorts, the changes in $\mathrm{CD}^{+} \mathrm{T}$ cells reached statistical significance only in the controls. Furthermore, absolute numbers, as well as proportions of $\mathrm{ROR}_{\mathrm{yt}}{ }^{+} \mathrm{CD}^{+}$and $\mathrm{CD}^{+} \mathrm{T}$ cells, were higher (not significant) in controls than in daclizumabtreated patients (figure 3 , please note differences in scales).

Cellular Ag specificity. Both cohorts had preexisting immunity to Flu-HA, as evidenced by high stimulation indices (ratio of numbers of proliferating cells in the condition with $\mathrm{Ag}$, divided by background proliferation observed in the wells where no exogenous $\mathrm{Ag}$ was added) observed already at D0, before administration of the vaccine (figure 4). In fact, the difference in proliferation of T cells or B cells to Flu-HA Ag between D0 and D7 did not reach statistical significance in either cohort. We also observed robust proliferation to CMV and EBV in the control group but not in daclizumabtreated patients. Neither cohort demonstrated significant proliferation to complex autoantigen, brain homogenate.

Humoral immunity to Afluria vaccine. Neutralizing $\mathrm{Ab}$ titers to the 3 viral variants present in 2013 Afluria vaccine (i.e., 2 A strains: A/CA/2009 and A/Victoria/361/2011; one $B$ strain: B/Mass/02/2012) were assessed before vaccination (D0) and 7 (D7) and 180 days (D180) postvaccination. Consistent with our data obtained in $\mathrm{T}$ cell specificity assays, we observed that all studied participants had preexisting immunity (i.e., $\mathrm{Ab}$ titers $\geq 1: 40$ ) to at least one of the viral variants (figure 5A). In the control group, 9 of $42(21.4 \%)$ possible patient/variant combinations did not fulfill criteria for seroprotection at D0. Nine of $9(100 \%)$ patient/variant pairs from the control group that did not have preexisting immunity seroconverted (i.e., achieved $\geq 4$-fold increase in $\mathrm{Ab}$ titers) at D7 postimmunization. The average fold increase in $\mathrm{Ab}$ titers in the newly seroconverted group was 356. In daclizumab-treated patients, 8 of
$51(15.7 \%)$ patient/variant combinations (note that because of long-distance travel, we had D7 follow-up data only on 17 daclizumab-treated patients) did not fulfill criteria for seroprotection at D0. Seven of 8 $(87.5 \%)$ patient/variant pairs that did not have preexisting immunity seroconverted at D7 postimmunization. The average fold increase in $\mathrm{Ab}$ titers in this group was 987. The seroconversion rate for both groups was highly significant (figure 5B).

DISCUSSION DAC-HYP is emerging therapy for RRMS. ${ }^{1,2,13}$ As our armamentarium of therapeutic agents for this disease expands, their efficacy is carefully weighed against their side effects. Because none of the current or emerging pharmaceutical agents are curative, patients with RRMS are expected to receive therapy for years or decades and the effects of such long-term treatment on immune responses against infectious agents or vaccinations need to be considered. Clinical trials of daclizumab (Zenapax $)^{13,14}$ as well as of its new formulation DAC-HYP ${ }^{1,2,15}$ recorded a mild but reproducible increase in infectious complications, although opportunistic infections have not been reported. These in vivo observations are consistent with in vitro mechanisms of action, which include inhibition of trans-presentation of IL-2 by autologous DCs to primed $\mathrm{T}$ cells, leading to decreased generation of Ag-specific $\mathrm{CD}^{+}$and $\mathrm{CD}^{+} \mathrm{T}$ effectors. ${ }^{5,22}$ Activated $\mathrm{T}$ cell responses are further affected during daclizumab therapy by cytotoxicity of expanded immunoregulatory CD56 bright $\mathrm{NK}$ cells. ${ }^{16,17}$ However, in contrast to mice, CD25 is not necessary for development of human Ab-secreting memory B cells or plasma cells and, consequently, no inhibitory effects of daclizumab on serum IgM, IgA, IgE, and IgG levels (IgG isotypes) have been observed. ${ }^{13}$ This is in contrast to intrathecal $\mathrm{Ab}$ production (measured as IgG index), which declined upon daclizumab treatment of $\mathrm{MS}^{7}$ suggesting that daclizumab targets pathogenic immune responses mediating autoimmunity more potently than it does immune responses in general. Nevertheless, the extent to which daclizumab therapy interferes with development of protective immunity has not been directly investigated.

Although current analysis of cellular and humoral immune responses to seasonal influenza vaccination was performed within the context of an open-label clinical trial, all samples were processed and analyzed in blinded fashion. The major drawback of the current study is the limited number of participants. It is practically impossible to apply complex functional studies, performed on freshly isolated $\mathrm{T}$ cells, to a large number of participants. Our previous studies 
Figure 5 Flu immunization-induced changes in neutralizing Ab titers against 3 viral variants present in Afluria 2013 vaccine

A

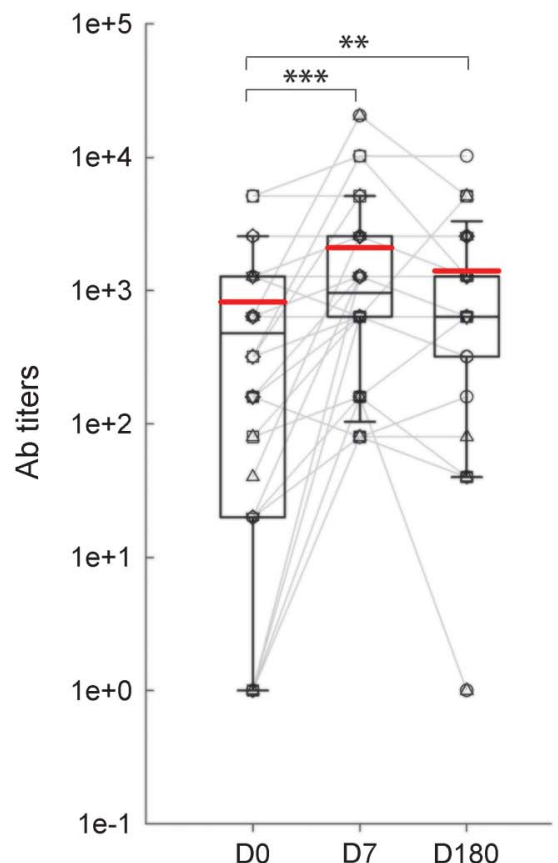

B

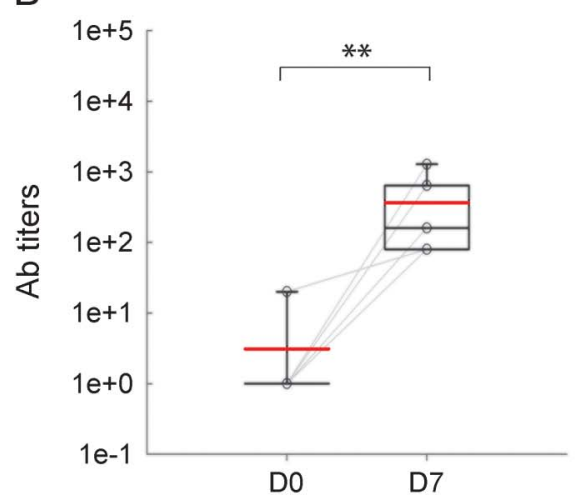

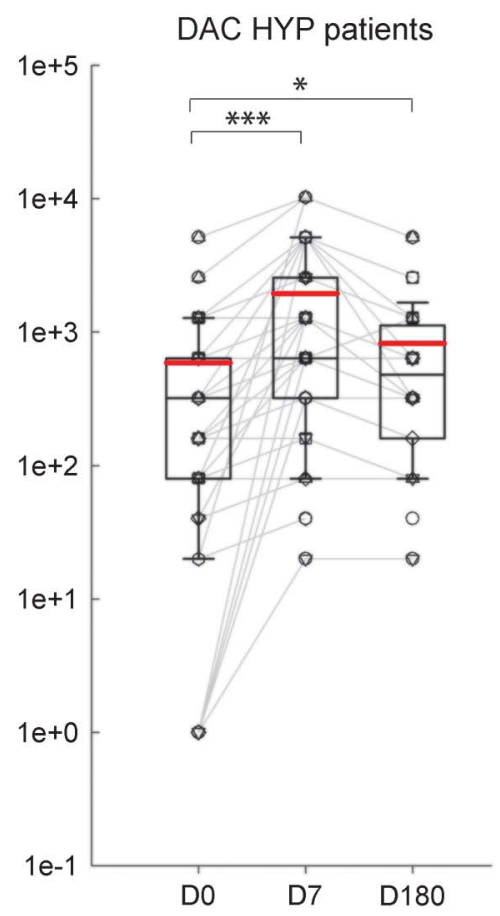

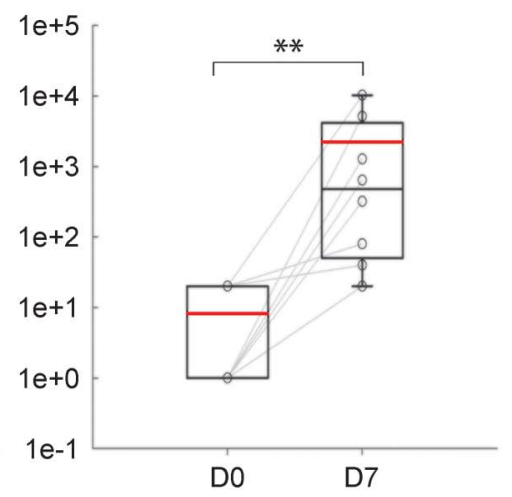

(A) The change in neutralizing Ab titers to all 3 viruses present in the Afluria vaccine between DO (before vaccination), and 7 days (D7) and 180 days (D180) postvaccination graphed separately for control group (left panels) and DAC-HYP-treated patients (right panels). (B) Subgroup of control (left panel) and daclizumab-treated participants (right panel) who did not have preexisting $\mathrm{Ab}$ immunity at $\mathrm{DO}$ to at least one of the viral variants are plotted separately, to demonstrate that all participants increased neutralizing Ab titers 7 days postvaccination (D7). The vertical box plots show the median and $25 \%-75 \%$ range, while the whiskers reflect minimum and maximum values for each diagnostic group. The scatter dot plots correspond to individual patient's data. $* p<0.05, * * 0.001<p<0.05, * * * p<0.001$. $\mathrm{Ab}=$ antibody; DAC-HYP $=$ daclizumab high-yield process.

demonstrated that reproducible results for withinparticipant variability can be obtained with comparable sample sizes (i.e., 10-20 participants). ${ }^{9} 16,17,25$ Furthermore, our diverse assays were complementary and the results are consistent across different assays.

We observed that all studied participants from both cohorts had preexisting cellular and humoral immunity to at least one of the 3 viral variants present in the 2013 Afluria vaccine. This explains the rapid activation of adaptive immune responses, measured

by immunophenotyping of blood samples. Using this Ag-nonspecific assay, we observed greater activation of $\mathrm{CD}^{+}$and $\mathrm{CD}^{+}{ }^{+} \mathrm{T}$ cells in controls, as compared to daclizumab-treated patients with MS. Correspondingly, in Ag-specific assays, we also observed greater $\mathrm{CD}^{+}$and $\mathrm{CD}^{+} \mathrm{T}$ cell reactivity to multiple tested $\mathrm{Ag}$ in the control cohort as compared to daclizumabtreated patients. Using autologous serum assured that $T$ cell activation occurred in the presence of physiologic concentrations of daclizumab, thus mimicking the in vivo situation as much as possible. Overall, the obtained results are consistent with previously described inhibition of DC-driven activation of $\mathrm{Ag}$ specific $\mathrm{T}$ cells, ${ }^{5}$ explaining the decreased proliferation of all $\mathrm{CD}^{+}{ }^{+}$and $\mathrm{CD}^{+} \mathrm{T}$ cells, irrespective of the Ag studied. We do not believe that our data suggest that daclizumab-treated patients with MS have lower preexisting immunity to EBV or CMV because we have investigated this issue previously using an assay that bypasses effect of daclizumab on DCs and observed comparable levels of $\mathrm{CD}^{+}$and $\mathrm{CD}^{+} \mathrm{T}$ cell reactivity to $\mathrm{EBV}$ and $\mathrm{CMV}$ in the blood of daclizumab-treated and untreated patients with MS. ${ }^{22}$

The study design also allowed us to investigate the intriguing possibility that IL-2 signaling blocks differentiation of T cells to Th17 effectors. ${ }^{24}$ Because daclizumab blocks high-affinity IL-2 signaling in human $\mathrm{T}$ cells, ${ }^{9}$ if the above-mentioned mechanism occurred in humans, one could expect increased generation of Th17 effectors in patients on daclizumab therapy. To avoid nonphysiologic changes introduced by a long in vitro culture, we focused on the $\mathrm{T}$ cell expression of the master regulator of Th17 lineage, ROR $\gamma$ t. Although we observed transient upregulation of ROR $\gamma t$ intracellular expression in $\mathrm{CD}^{+}$ and $\mathrm{CD}^{+} \mathrm{T}$ cells, which coincided with their activation (as measured by expression of activation markers HLA-DR, CD69, and CD38) at D1 postimmunization, this increase was actually more robust (and highly statistically significant) in controls as compared to the daclizumab-treated cohort. This suggests that high-affinity IL-2 signaling does not have an inhibitory role on Th17 differentiation in humans, a result supported by a recent study of participants with different genetic variants of IL2RA. ${ }^{26}$ Alternatively, the decrease in ROR $\gamma t$ induction could have resulted from the aforementioned inhibitory effect of daclizumab on DC-mediated T cell activation.

In contrast to the observed inhibitory role on $\mathrm{T}$ cells, the expansion of memory B cells (immunophenotyping results) and increase in neutralizing $\mathrm{Ab}$ titers were not affected by daclizumab therapy. All but one daclizumab-treated participant who did not have preexisting protective immunity was able to achieve seroprotection at D7 postimmunization and the 
seroconversion titers were actually higher in daclizumab as compared to control cohorts. These results indicate that humoral immunity is largely unaffected by daclizumab therapy.

The current study provides strong support to previously described inhibitory mechanisms of daclizumab on $\mathrm{T}$ cell immunity, while demonstrating that this inhibitory effect is not complete and allows generation of protective immunity against environmental $\mathrm{Ag}$ such as seasonal influenza immunization. However, because of preexisting immunity in the majority of participants, the question of whether daclizumab therapy inhibits development of $\mathrm{T}$ cell responses to neo-antigens remains open and may need to be investigated in future studies.

\section{AUTHOR CONTRIBUTIONS}

Dr. Lin: study concept and design, acquisition of data, analysis and interpretation, critical revision of the manuscript for important intellectual content. Mrs. Winokur: acquisition of data. Mr. Blake: acquisition of data. Dr. Wu: Statistical analysis. Mrs. Manischewitz: acquisition of data. Mrs. King: acquisition of data. Mrs. Romm: acquisition of data. Dr. Golding: study concept and design. Dr. Bielekova: study concept and design, critical revision of the manuscript for important intellectual content, study supervision.

\section{ACKNOWLEDGMENT}

The authors thank Anne Mayfield for scheduling patients and Jenifer Dwyer, Jamie Cherup, and the clinical team for sample collection and expert patient care.

\section{STUDY FUNDING}

The study was supported by the intramural research program of the National Institute of Neurological Disorders and Stroke (NINDS) and collaborative agreement (CRADA) between NINDS and AbbVie/Biogen Idec.

\section{DISCLOSURE}

Y.C. Lin, P. Winokur, A. Blake, T. Wu, and J. Manischewitz report no disclosures. L.R. King is employed by the FDA. E. Romm and H. Golding report no disclosures. B. Bielekova is coinventor on several NIH patents related to daclizumab and as such has received patent royalty payments from the NIH, and received research support from the NIH, Biogen/AbbVie, and Santhera Pharmaceuticals. Go to Neurology.org/nn for full disclosure forms.

Received July 31, 2015. Accepted in final form November 25, 2015.

\section{REFERENCES}

1. Gold R, Giovannoni G, Selmaj K, et al. Daclizumab highyield process in relapsing-remitting multiple sclerosis (SELECT): a randomised, double-blind, placebo-controlled trial. Lancet 2013;381:2167-2175.

2. Giovannoni G, Gold R, Selmaj K, et al. Daclizumab highyield process in relapsing-remitting multiple sclerosis (SELECTION): a multicentre, randomised, double-blind extension trial. Lancet Neurol 2014;13:472-481.

3. Waldmann TA, Goldman CK, Bongiovanni KF, et al. Therapy of patients with human T-cell lymphotrophic virus $\mathrm{I}$-induced adult $\mathrm{T}$-cell leukemia with anti-Tac, a monoclonal antibody to the receptor for interleukin-2. Blood 1988;72:1805-1816

4. Caudy AA, Reddy ST, Chatila T, Atkinson JP, Verbsky JW. CD25 deficiency causes an immune dysregulation, polyendocrinopathy, enteropathy, X-linked-like syndrome, and defective IL-10 expression from CD4 lymphocytes. J Allergy Clin Immunol 2007;119:482-487.
5. Wuest SC, Edwan JH, Martin JF, et al. A role for interleukin-2 trans-presentation in dendritic cellmediated $\mathrm{T}$ cell activation in humans, as revealed by daclizumab therapy. Nat Med 2011;17:604-609.

6. Lenardo MJ. Interleukin-2 programs mouse $\mathrm{T}$ lymphocytes for apoptosis. Nature 1991;353:858-861.

7. Perry JS, Han S, Xu Q, et al. Inhibition of LTi cell development by CD25 blockade is associated with decreased intrathecal inflammation in multiple sclerosis. Sci Transl Med 2012;4:145ra106.

8. Oh U, Blevins G, Griffith C, et al. Regulatory T cells are reduced during anti-CD25 antibody treatment of multiple sclerosis. Arch Neurol 2009;66:471-479.

9. Martin JF, Perry JS, Jakhete NR, Wang X, Bielekova B. An IL-2 paradox: blocking CD25 on T cells induces IL-2driven activation of CD56(bright) NK cells. J Immunol 2010;185:1311-1320.

10. Wakabayashi K, Lian ZX, Moritoki Y, et al. IL-2 receptor alpha $(-/-)$ mice and the development of primary biliary cirrhosis. Hepatology 2006;44:1240-1249.

11. Roifman CM. Human IL-2 receptor alpha chain deficiency. Pediatr Res 2000;48:6-11.

12. Sharfe N, Dadi HK, Shahar M, Roifman CM. Human immune disorder arising from mutation of the alpha chain of the interleukin-2 receptor. Proc Natl Acad Sci USA 1997;94:3168-3171.

13. Bielekova B, Richert N, Howard T, et al. Humanized antiCD25 (daclizumab) inhibits disease activity in multiple sclerosis patients failing to respond to interferon-beta. Proc Natl Acad Sci USA 2004;101:8705-8708.

14. Bielekova B, Howard T, Packer AN, et al. Effect of antiCD25 antibody daclizumab in the inhibition of inflammation and stabilization of disease progression in multiple sclerosis. Arch Neurol 2009;66:483-489.

15. Wynn D, Kaufman M, Montalban X, et al. Daclizumab in active relapsing multiple sclerosis (CHOICE study): a phase 2, randomised, double-blind, placebo-controlled, add-on trial with interferon beta. Lancet Neurol 2010;9: 381-390.

16. Bielekova B, Catalfamo M, Reichert-Scrivner S, et al. Regulatory CD56bright natural killer cells mediate immunomodulatory effects of IL-2R-alpha-targeted therapy (daclizumab) in multiple sclerosis. Proc Natl Acad Sci USA 2006;103:5941-5946.

17. Jiang W, Chai NR, Maric D, Bielekova B. Unexpected role for granzyme $\mathrm{K}$ in $\mathrm{CD} 56$ bright $\mathrm{NK}$ cell-mediated immunoregulation of multiple sclerosis. J Immunol 2011;187:781-790.

18. Bielekova B. Daclizumab therapy for multiple sclerosis. Neurotherapeutics 2013;10:55-67.

19. Polman $\mathrm{CH}$, Reingold SC, Banwell B, et al. Diagnostic criteria for multiple sclerosis: 2010 revisions to the McDonald criteria. Ann Neurol 2011;69:292-302.

20. Tsang JS, Schwartzberg PL, Kotliarov Y, et al. Global analyses of human immune variation reveal baseline predictors of postvaccination responses. Cell 2014;157:499-513.

21. Han S, Lin YC, Wu T, et al. Comprehensive immunophenotyping of cerebrospinal fluid cells in patients with neuroimmunological diseases. J Immunol 2014;192:2551-2563.

22. Wuest SC, Mexhitaj I, Chai NR, et al. A complex role of herpes viruses in the disease process of multiple sclerosis. PLoS One 2014;9:e105434.

23. Rowe T, Abernathy RA, Hu-Primmer J, et al. Detection of antibody to avian influenza $\mathrm{A}(\mathrm{H} 5 \mathrm{~N} 1)$ virus in human 
serum by using a combination of serologic assays. J Clin Microbiol 1999;37:937-943.

24. Laurence A, Tato CM, Davidson TS, et al. Interleukin-2 signaling via STAT5 constrains T helper 17 cell generation. Immunity 2007;26:371-381.

25. Bielekova B, Goodwin B, Richert N, et al. Encephalitogenic potential of the myelin basic protein peptide (amino acids 83-99) in multiple sclerosis: results of a phase II clinical trial with an altered peptide ligand. Nat Med 2000;6:1167-1175.

26. Hartmann FJ, Khademi M, Aram J, et al. Multiple sclerosis-associated IL2RA polymorphism controls GMCSF production in human $\mathrm{TH}$ cells. Nat Commun 2014;5:5056. 


\title{
Neurology \\ Neuroimmunology \& Neuroinflammation
}

\author{
Patients with MS under daclizumab therapy mount normal immune responses to \\ influenza vaccination \\ Yen Chih Lin, Paige Winokur, Andrew Blake, et al. \\ Neurol Neuroimmunol Neuroinflamm 2016;3; \\ DOI 10.1212/NXI.0000000000000196
}

This information is current as of January 27, 2016

\section{Updated Information \& Services}

Supplementary Material

References

Subspecialty Collections

Permissions \& Licensing

Reprints including high resolution figures, can be found at:

http://nn.neurology.org/content/3/1/e196.full.html

Supplementary material can be found at:

http://nn.neurology.org/content/suppl/2016/01/27/3.1.e196.DC1

This article cites 26 articles, 9 of which you can access for free at: http://nn.neurology.org/content/3/1/e196.full.html\#\#ref-list-1

This article, along with others on similar topics, appears in the following collection(s):

Cerebrospinal Fluid

http://nn.neurology.org//cgi/collection/cerebrospinal_fluid

Multiple sclerosis

http://nn.neurology.org//cgi/collection/multiple_sclerosis

Information about reproducing this article in parts (figures,tables) or in its entirety can be found online at:

http://nn.neurology.org/misc/about.xhtml\#permissions

Information about ordering reprints can be found online:

http://nn.neurology.org/misc/addir.xhtml\#reprintsus

Neurol Neuroimmunol Neuroinflamm is an official journal of the American Academy of Neurology.

Published since April 2014, it is an open-access, online-only, continuous publication journal. Copyright $\odot$ 2016 American Academy of Neurology. All rights reserved. Online ISSN: 2332-7812.

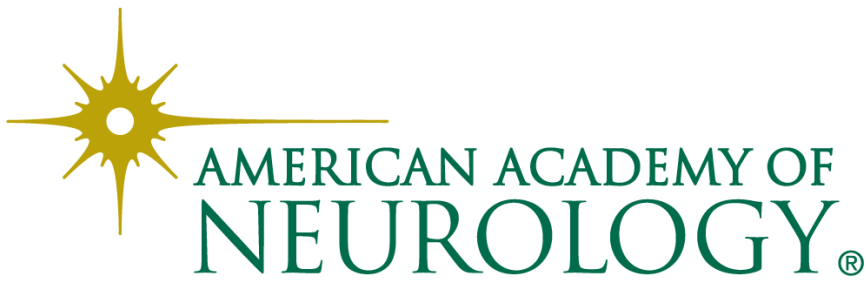

